Психология. Журнал Высшей школы экономики.

2016. T. 13. № 3. С. 498-518.

\title{
Cmambu
}

\section{МЕТОД ОЦЕНКИ ПРИВЯЗАННОСТИ К ДОМУ}

\author{
С.И. РЕЗНИЧЕНКО ${ }^{\text {a }}$ С.К. НАРТОВА-БОЧАВЕР ${ }^{\mathrm{b}}$, В.Б. КУЗНЕЦОВА \\ ${ }^{a}$ ФГБОУ ВО «Московский государственный психолого-педагогический университет», 127051, \\ Россия, Москва, ул. Сретенка, 29 \\ ${ }^{b}$ Национальный исследовательский университет «Высшая школа экономики», 101000, Россия, \\ Москва, ул. Мясницкая, 20 \\ ${ }^{c}$ ФГБУ НИИ физиологии и фундаментальной медицины СО РАМН, 630117, Россия, Новосибирск, \\ ул. Тимакова, 4
}

\section{Резюме}

Аргументируется высокая актуальность изучения привязанности человека к дому как интердисциплинарного и многослойного феномена, отражающего реципрокность отношений человека и среды его жизнедеятельности и имеющего регуляторный и валеологический смысл для личности. Подробно проанализирована проблематика феномена привязанности к дому, который представляет собой частный вариант привязанности к месту, обсуждены многоуровневость понятия дома как объекта функциональной, эмоциональной и символической привязанности, рассмотрены основные структурные компоненты, формирующие его, такие как идентификация с местом, чувство места, зависимость от места. Изложены методологические предпосылки и процесс создания опросника Привязанности к дому, описаны его концептуальная, эмпирическая и факторная модели. Приведены процедура и результаты пилотного исследования ( $\left.\mathrm{N}=287, \mathrm{M}_{\text {возр }}=21.5, \mathrm{SD}_{\text {возр }}=9.2\right)$ по валидизации опросника (факторного анализа, внутренней согласованности), дана описательная статистика. Представлены результаты основного исследования, цель которого заключалась в анализе конструктной валидности опросника. Валидизация включала проверку наличия корреляционных связей между привязанностью к дому и уровнем функциональности домашней среды. Описан анализ возрастной специфики (были определены три возрастные группы - юноши, представители ранней и средней взрослости). С возрастом взаимосвязи между привязанностью к дому и его функциональностью наращиваются. Кроме того, они модерируются и полом: привязанность к дому у женщин связана с защищенностью и возможностью саморазвития в домашней среде, а у мужчин - с удобством и комфортом жилища. В заключение дискутируются возможности, ограничения и перспективы использования авторского опросника.

Ключевые слова: экологическая психология, привязанность к дому, опросник, функциональность, конвергентная валидность, возрастная и гендерная специфика.

Работа подготовлена при поддержке Российского научного фонда, проект № 14-18-02163. 
В контексте субъектно-средовой проблематики широко известен феномен привязанности к месту (place attachment). Этот концепт интерпарадигмален и связан с широким кругом научных дисциплин, таких как социальная психология, социология, экология, антропология и общественная (гуманитарная) география. Согласно Д. Уильямсу, привязанность к месту является «системой смыслов, верований, символов, ценностей и чувств», ассоциированных у человека или группы людей с тем или иным местом (Williams, Stewart, 1998, p. 19).

Понятие привязанности к месту трактуется очень широко и разноуровнево:

- как осознанный характер отношений человека к окружающей среде в целом, в частности, к сообществу, культуре, природе, техносфере, где привязанность - результат «эмоциональных, когнитивных, социальных, культурных и поведенческих процессов и факторов» (Pruneau et al., 1999, p. 27);

- как пространство, наполненное индивидуальным смыслом, который появляется в ходе длительного взаимодействия, узнавания и сигнификации человеком места (Tuan, 1977);

- как эмоциональное отношение человека к местной природе и ландшафту (Inglis, 2008);

- как ориентирующий и направляющий жизнь структурный элемент иерархии человеческих ценностей, которая зависит от значений, культурных и этических норм, заданных в пространстве (в первую очередь, конечно, социальном) (Broudehoux, 2001);
• как один из ключевых факторов, отражающих индивидуальность, наряду с жизненным опытом и личностным развитием (Bow, Buys, 2003);

- как генетически заложенная глубокая связь с природой привычной для нас местности (в терминологии гарвардского биолога Э. Вилсона - биофилия). Или же, наоборот, биофобия, заключающаяся в отвращении к природе и стремлении жить в высокотехнологичной и цивилизованной среде (Orr, 1994, p. 39).

Под «местом» чаще всего понимается реальная или воссозданная в памяти человека территориальная единица - страна, район, зона рекреации, например, парк или же дом. Хотя «место», как правило, подразумевает географическое пространство, оно пронизано индивидуальными смыслами для человека, которые возникают только при условии взаимодействия и жизнедеятельности в этом месте (Kaltenborn, Bjerke, 2002). Кажется удивительным, но привязанность к месту практически не изучалась в психологии домашней среды, хотя очевидно, что дом для человека является первичным бытийным пространством и значительным потенциальным объектом привязанности к месту, местом, где чаще всего возникает субъект-средовое взаимодействие - главное условие формирования привязанности к месту. Тема дома является архетипическим предметом интерпретаций, что подтверждается огромным количеством примеров из литературы и кинематографа, где дом - это олицетворение умиротворения, истории, 
уклада жизни и уюта (НартоваБочавер, 2016).

\section{Дом как объект привязанности}

Дом как жилище, характеризуемое своим предметно-пространственным содержанием и архитектурой, - это материальный ресурс для утоления базовых потребностей человека во сне, безопасности, отдыхе, комфорте. При этом привязанность к нему может поддерживаться мерой его функциональности. Взгляд на жилую среду как на источник функциональных возможностей, облегчающих повседневную деятельность, типичен для гуманитарной географии, где «место» (средовой объект привязанности) интерпретируется как физический объект с его пространственно-содержательной организацией и функциональными характеристиками. В составе привязанности к месту традиционно выделяют функииональную привязанность, или феномен зависимости от места (place dependence). Д. Стоколс и С. Шумахер определяют ее так: «воспринимаемая обитателем сила связи между ним и местом... двунаправленный процесс, в ходе которого человек оценивает качество и комфортность текущего места и относительное качество сопоставимых мест» (Stokols, Shumaker, 1981, p. 447). Функциональная привязанность к дому связана с деятельностью субъекта в домашней среде и степенью функциональности среды, соответствия ее условий потребностям человека, например, в отдыхе или саморазвитии и т.п. Функциональная привязанность к дому ориентирована на цели и потребности человека. Прежде всего, имеются в виду потребности в выполнении определенных видов деятельности, например, возможности воспитания детей в домашних условиях или проведения досуга или возможности заниматься спортом, хобби, работать дома и другие функциональные возможности домашней среды, обеспечивающие обитателю чувство комфорта, удобства и стабильности. Функциональная привязанность к дому находится в тесной связи с поведением и стилем жизни человека: очевидно, что наличие/отсутствие определенных условий в среде диктует хабитуальность, привычки, ритуалы и образ жизни человека в целом (Нартова-Бочавер, 2006; Резниченко, 2014).

Дом как объект эмоциональносмысловой привязанности и идентификации включает чувства, воспоминания, ассоциации, события истории жизни обитателя, связанные с образом дома, и таит в себе удовлетворение потребностей экзистенциального порядка - в хранении семейной истории, социальных интеракциях, самопрезентации, персонализации и многом другом. (Резниченко, 2013б). Природа привязанности к дому есть феномен, конструируемый в ходе взаимодействия человека с домом, а значит, динамичный, поскольку для людей важно не само жилище как территориальный или материальный объект, а то, какие личностные смыслы оно в себе несет для формирования и поддержания личностной или групповой идентичности и личностных смыслов (Rodman, 2003).

Эмоционально-смысловой характер привязанности к месту типичен 
для исследователей в области средовой психологии, где «место» - дом, образовательное учреждение, парк или любой другой средовой объект это отражение внутренних установок, предпочтений, ценностей. Эмоционально-смысловая привязанность может быть оформлена в самостоятельный компонент в структуре мотивационной основы привязанности к дому и определяется как сложный конгломерат раздумий и чувств по поводу конкретных физических параметров домашней среды и их соответствия личностным смыслам и жизненным целям ее обитателя. Вариантом проявления эмоционально-смысловой привязанности является идентификация со средовым объектом привязанности (place identity) - позитивный процесс, при котором среда жизнедеятельности является личностным элементом «образа Я» любого человека. В отличие от функциональной привязанности к дому эмоционально-смысловая связь с домом может поддерживаться глубоко субъективными когнитивными факторами и быть иррациональной. Например, человек может любить свой дом (как может показаться окружающим - одинокий, пустой, неудобный и обветшалый) просто потому, что это место напоминает ему о времени, проведенном с родителями, о семейных вечерах и т.п. Процесс идентификации с домом сильно связан с воспоминаниями детства, анализом жизненных событий, произошедших в жилой среде во взрослом возрасте, с общественной оценкой качества жилой среды (например, «дом, где живут порядочные люди»), с символическим наполнением дома (насле- дие, традиции, ритуалы), с характеристиками социального капитала (оформленность соседских отношений, устойчивость социальных норм и правил или уровень доверия между людьми) (Johnson, 1998).

Необходимо отметить, что традиционно выделяемые формы привязанности к дому - функциональная и эмоционально-смысловая - условно могут быть самостоятельными явлениями. Так, например, удовлетворенность функциональными характеристиками домашней среды и выбор ее как оптимального плацдарма для определенных видов деятельности не означают, что человек привязан к дому. Функциональная и эмоционально-смысловая привязанность вообще весьма условны и не имеют четких границ; это реципрокные и тесно взаимодействующие конструкты, эмпирически сложно отделимые друг от друга.

Проявления привязанности, описанные авторами, также разнообразны, симптоматичны и не интегрированы в единую модель. Наиболее часто к «признакам» привязанности к дому или другой среде жизнедеятельности относят позитивное отношение к месту, легкость в ориентировании и узнавании в среде, а также обширные знания об истории, традициях, культуре, природе предмета привязанности, частое посещение, активное участие в общественной жизни и развитое экоцентрическое сознание; стремление человека сигнифицировать среду, опредмечивая ее значимость через рассказы, записи, изображения на открытках. Отмечается, что привязанность к месту сопровождается экологическим поведением (pro-environmental 
behavior) человека в среде и стремлением к сохранению статус-кво места проживания. Это также справедливо и в отношении домашней среды (Meesters, 2009).

Индивидуальными предикторами привязанности к дому могут быть возраст, образование, длительность проживания, символическая значимость и ассоциативная связь, экологичность сознания (Jorgensen, Stedman, 2006), установки на ценность семейных связей, преемственности и истории поколений (Hou et al., 2005), жизненный опыт (Inglis, 2008), участие в местном самоуправлении (например, в рамках деятельности ТСЖ) (Драганова и др., 2002) и др.

Итак, на наш взгляд, позитивное отношение человека к его дому может быть описано при помощи феномена привязанности к дому переживания того, что дом со всеми его предметно-пространственными, социальными и психологическими особенностями оценивается как близкий и родной, поддерживающий целостность и аутентичность, комфортный и функциональный, как цель возвращения и тыл. Привязанность к дому - сложный комплекс позитивных чувств и переживаний по отношению к дому как к личностно значимому месту (в символическом, функциональном, эмоциональном планах), влияющий на поведение и ценности, направляющий жизнь, поддерживающий психологическое благополучие человека. Важно иметь инструмент изучения степени удовлетворенности домашней средой проживания, привязанности или отчужденности от дома. За рубежом привязанность к месту и тем более к дому как само- стоятельный конструкт изучается редко, чаще - при помощи интервью в технике «лестница», проективных методов или символического анализа, что является крайне трудоемким и сложным процессом для объективной категоризации результатов.

Мы поставили перед собой задачу разработать шкальный метод оценки привязанности к дому.

\section{Методологические предпосылки создания опросника}

Анализ методических инструментов обнаружил, что методики, непосредственно измеряющие степень привязанности к дому, отсутствуют. Между тем имеются теоретические научные установки на рассмотрение привязанности к дому как варианта феномена привязанности к месту. Феномен привязанности к дому в целом имеет схожие с привязанностью к месту свойства, механизмы и мотивационные основы формирования, хотя может иметь свою специфику или структуру. Например, факторы социальной или поселенческой идентичности могут иметь значительно меньший или больший контрибуционный потенциал в формировании привязанности к дому, чем к городу, парку или другому месту, поскольку социальные интеракции и капитал в каждом из этих территориальных единиц имеют свои особенности.

Создание опросника предварял анализ немногочисленных методик, измеряющих привязанность к месту и разработанных в русле гуманитарной географии и рекреационной психологии. Общей особенностью методик является то, что они базируются 
на интегральных идеях антропоцентризма, биоцентризма и экоцентризма и психологии среды и изучают привязанность к крупным территориальным единицам - району, местной природе, общественным местам рекреации.

Одной из таких методик является Шкала рекреационных предпочтений (Recreational Attachment Scale), измеряющая три мотивационных фактора, формирующих у людей стремление посещать определенное место рекреации снова и снова: 1) средовой - общая удовлетворенность местом и его физическими качествами вне оценки его функционального или смыслового значения для человека; 2) деятельностный оценка места как оптимального для занятия определенными видами деятельности; 3) социальный - вовлеченность и удовлетворенность социальной жизнью и отношениями, бытующими в месте. Подобная факторная структура может в большей степени объяснить, насколько предпочтительна предметно-пространственная организация места или его функциональность, т.е. функциональный компонент привязанности, и в меньшей степени - значимость эмоционально-смыслового компонента привязанности (Williams et al., 1992).

Прототипом шкалы привязанности к дому стал опросник «Привязанность к месту», созданный Джуди Инглиз на основе Шкалы рекреационных предпочтений. Опросник изучает меру привязанности к определенному природному объекту (национальный парк, река, озеро) в категориях «родное/чужое», «близкое/вызывающее отчуждение». В соответствии с концептуальной основой автора и проведенной эмпирической верификацией структуры опросника он имеет пятифакторную структуру: 1) шкала зависимости от места (Place Dependence Factor), описывающая удовлетворенность человека степенью соответствия функциональности среды имеющимся потребностям в определенных видах деятельности, в том числе отдыхе; 2) шкала идентификации с местом (Place Identity Factor); 3) шкала отсутствия привязанности (отчужденности) (No Attachment Factor); 4) шкала восприятия исключительности места (Site Dependent Factor), описывающая восприятие функциональных возможностей места в дихотомии универсальное/уникальное; 5) шкала социальной привязанности или социальной принадлежности к местному сообществу (Community Identity and Commitment Factor). Заметим, что только три шкалы из пяти имеют хорошие значения надежности и самосогласованности. А, например, шкалы 4 и 5 были выделены автором априорно и содержат лишь один пункт, что затрудняет оценку репрезентативности шкалы. Сопряженный с возрастным или гендерным факторами сравнительный анализ показателей привязанности к месту автором не приводится.

Резюмируя, отметим, что факторная структура конструкта привязанности к месту неоднозначна, число факторов варьируется в зависимости от априорных концептуальных установок авторов и особенностей популяции. 


\section{Пилотное исследование: определение содержания и структуры опросника}

При разработке банка утверждений для нашего опросника мы модифицировали пункты теста Дж. Инглиз, переставив акценты с места вообще на дом (например: «Я чувствую, что мой дом - это часть меня»). Степень согласия с утверждениями оценивалась по 5-балльной шкале Лайкерта. В пилотном исследовании приняли участие 287 респондентов (30\% мужского пола) в возрасте от 11 до 63 лет $\left(\mathrm{M}_{\text {возр }}=21.5\right.$, $\left.\mathrm{SD}_{\text {возр }}=9.2\right)$.

В силу того, что конструкт привязанности к месту многослойный, сложно определяемый и эмпирически неоднозначно описанный, мы не ставили перед собой цель воспроизвести исходную факторную структуру опросника и психометрические особенности. Структура опросника Привязанности к дому изучалась при помощи эксплораторного факторного анализа матрицы корреляций ответов на отдельные вопросы по методу главных компонент с вращением Varimax. Предварительный анализ показал, что, согласно тесту КМО (0.91) и тесту Бартлетта $(p<0.001)$, размер и идентичность выборки адекватны данному анализу. Факторный анализ шкалы показал, что, согласно критерию Кайзера (собственные значения > 1), выделяются четыре фактора, в то же время тест «каменистой осыпи» (scree plot), демонстрирующий собственные значения факторов, полученных в результате анализа главных компонент до вращения матрицы, указал на однофакторное решение (см. таблицу 1). Кроме того, множественный анализ соответствий (Multiple Correspondence Analysis, MCA) - метод, который, не накладывая никаких ограничений на данные, позволяет получить четкое представление об их структуре (Abdi, Valentin, 2007), показал, что однофакторная модель имела наивысшую альфу Кронбаха $(\alpha=0.93)$, в то время как модели с возрастающим числом факторов от двух до четырех отчетливо снижали индекс внутренней согласованности (альфа была равна $0.88,0.71,0.67$ соответственно). Мы проверили две модели, четырехфакторную, основанную на теоретических предпосылках, и однофакторную, основанную на результатах МСА, при помощи конфирматорного факторного анализа. Одним из критериев точного соответствия является показатель $\mathrm{CMIN} / \mathrm{DF}$, представляющий собой нормализованный $\chi^{2}$. Значения CMIN/DF ниже 3 указывают на удовлетворительное соответствие модели эмпирическим данным (Arbuckle, Worthke, 1999). Также использовались сравнительный индекс соответствия (CFI), инкрементный индекс соответствия (IFI) и квадратный корень ошибки приближения (RMSEA). Значения CFI и IFI выше 0.90 и RMSEA ниже 0.08 указывают на хорошее соответствие модели. Информационный критерий Акаике (AIC) используется для проверки как статистической доброкачественности соответствия (goodness of fit), так и числа параметров, которые должны быть приняты во внимание для достижения этого уровня соответствия при наложении ограничения на возрастание числа параметров. 
Чем ниже значение этого критерия, тем более предпочтительна модель (Ibid.).

Из таблицы 1 видно, что значения факторных нагрузок в четырехфакторной модели опросника не соответствуют принятым стандартам.

Во вторую модель были включены все семнадцать переменных, составляющих шкалу опросника и выделенных на основе эксплораторного факторного анализа. Для улучшения индексов соответствия модели были приняты во внимание индексы модификации, которые показали, что она может быть улучшена путем добавления одной ковариации ошибок: между пятым и девятым пунктом. Полученная в процессе модификации модель обладала хорошим соответствием эмпирическим данным, согласно индексам относительного соответствия, и, следовательно, наиболее адекватно соответствовала структуре опросника. Надежность шкалы опросника определяли с помощью коэффициента внутренней согласованности альфа Кронбаха. Внутренняя согласованность (коэффициент альфа Кронбаха) была высокой - 0.77 , однако если удалить три вопроса (Q13, Q14, Q15), которые грузились отрицательно по отношению к данной шкале, то альфа возрастала до 0.89, поэтому было принято решение полностью удалить эти пункты из дальнейшего анализа.

Таким образом, опросник Привязанности к дому включает 14 прямых вопросов и описывается одной шкалой, которая отражает общий уровень привязанности человека к его дому (см. Приложение).

Мы предполагаем, что редукция факторной структуры опросника (по сравнению со структурой опросников, определенных нами в качестве исходных) связана, прежде всего, с выбором в качестве предмета анализа отношения к дому, а не к общественным городским территориальным единицам.

Кроме того, искажение факторной структуры могло возникнуть как проявление этнических особенностей выбранной популяции. Идентификация с домом и удовлетворенность функциональностью дома (в терминологии Дж. Инглиз и других экологических психологов «зависимость от места») стали возможны только в последние несколько десятилетий в силу расширения возможностей украсить, сигнифицировать и персонализовать свой дом в

Таблица 1

Индексы соответствия моделей структуры опросника по результатам конфирматорного анализа

\begin{tabular}{|l|c|c|c|c|c|c|c|}
\hline \multicolumn{1}{|c|}{ Модель } & $\boldsymbol{\chi}^{2}$ & $\mathbf{d f}$ & $\mathbf{C M I N} / \mathbf{d f}$ & RMSEA & IFI & CFI & AIC \\
\hline Модель 1 (4 фактора) & $572.0^{*}$ & 10 & 52.2 & 0.443 & -3.55 & 0.000 & 572.0 \\
\hline Модель 2 (1 фактор) & $445.5^{*}$ & 119 & 3.7 & 0.098 & 0.844 & 0.842 & 547.5 \\
\hline $\begin{array}{l}\text { Модель 2а (1 фактор), } \\
\text { модифицированная }\end{array}$ & $387.5^{*}$ & 118 & 3.2 & 0.089 & 0.872 & 0.871 & 454.5 \\
\hline
\end{tabular}

${ }^{*} p<0.001$. 
соответствии со вкусами его обитателя, хотя до сих пор имеет место ряд бюрократических (например, ограничения БТИ по перепланировке квартиры, отдельные пункты градостроительного кодекса относительно украшения балконов, фасадов зданий) и социальных препон (посягательство на частное имущество и жизнь и т.п.), препятствующих независимому и ориентированному на собственные предпочтения выбору и моделированию облика частного жилища. Стоит учитывать и прямую зависимость индивидуализации дома от финансового и рыночного факторов: к сожалению, в России проектирование индивидуального жилого пространства доступно в основном только людям с хорошим достатком и в крупных городах. Мы предполагаем, что по этим же причинам восприятие исключительности дома как фактор привязанности не был подтвержден. Наконец, нивелирование в процессе факторного анализа шкалы социальной привязанности к дому, с нашей точки зрения, особенно типично для российского населения, особенно жителей мегаполиса с высокой ценностью приватности, стремящихся жить в своих домах отстраненно и закрыто, вне личностных контактов с соседями, не ориентируясь на интересы и предложения локального домашнего сообщества.

Мы предполагаем, что опросник привязанности к месту может иметь многомерную структуру, надежность и валидность его эмпирической модели как целостного конструкта экспериментально хорошо подтверждаются.

Гипотеза об отличии распределения от нормального проверялась с помощью критерия КолмогороваСмирнова. Статистически значимых отклонений от нормального распределения обнаружено не было. По массиву данных были получены следующие показатели мер центральной тенденции (см. таблицу 2).

Анализ репрезентативности опросника также включал сравнение данных возрастных и гендерных групп. В качестве сравниваемых из общей выборки ( $\mathrm{N}=168)$ были выделены две группы респондентов, различающиеся по гендерному признаку (89 женщин и 79 мужчин). Кроме того, достаточный объем выборки позволил выделить три группы респондентов,

Таблица 2

Описательная статистика опросника «Привязанность к дому» (14 пунктов)

\begin{tabular}{|l|c|}
\hline \multicolumn{1}{|c|}{ Показатели } & Значения по выборке \\
\hline Среднее & 3.73 \\
\hline Медиана & 3.80 \\
\hline Стандартное отклонение & 0.66 \\
\hline Асимметрия & -0.26 \\
\hline Эксцесс & -0.49 \\
\hline Z-критерий Колмогорова-Смирнова & 0.06 \\
\hline Асимптотическое значение & 0.05 \\
\hline
\end{tabular}


распределенных по возрасту. Первая группа - юноши и девушки от 17 до 20 лет $\left(\mathrm{N}=46, \mathrm{M}_{\text {возр }}=19.5, \mathrm{SD}_{\text {возр }}=0.56\right)$; вторая - молодые люди 21-29 лет $\left(\mathrm{N}=42, \mathrm{M}_{\text {возр }}=23.2, \mathrm{SD}_{\text {возр }}=2.22\right)$; третью группу составили люди от 30 до 50 лет $\left(\mathrm{N}=42, \mathrm{M}_{\text {возр }}=37.5, \mathrm{SD}_{\text {возр }}=5.67\right)$.

Сравнительный анализ при помощи непараметрического критерия Манна-Уитни в сравниваемых группах показал слабозначимые гендерные различия $(\mathrm{U}=-2.06 ; p<0.05)$ показателей привязанности с тенденцией к их увеличению в женской подвыборке: у женщин показатели привязанности к дому выше, чем у мужчин. Похожие результаты были получены и в исследованиях других авторов, а главным обоснованием такой тенденции является тот факт, что женщины, будучи вовлеченными в домашнее хозяйство и в обустройство домашнего быта, в принципе проводят больше времени в стенах дома, чем мужчины. В свою очередь, продолжительность и теснота взаимодействия с домашней средой формируют сильную привязанность (Rollero, De Piccoli, 2010). Проведенный дисперсионный анализ также демонстрирует статистически значимую взаимосвязь между полом $(\mathrm{F}=6.85 ; p=0.10)$ и уровнем привязанности.

Значимых различий в показателях привязанности к дому у представителей ранней, средней и поздней зрелости $(\mathrm{H}=0.27 ; p=0.87)$, сравниваемых с помощью критерия $\mathrm{H}$ Крускала-Уоллиса, обнаружено не было. По результатам дисперсионного анализа можно говорить о том, что вариативность показателей привязанности к домашней среде в различных возрастах также не высока ( $\mathrm{F}=$ $=0.04 ; p=0.95)$. Из определения привязанности ясно, что уровень привязанности не может являться универсальным показателем. Вероятно, уровень привязанности к дому гораздо сильнее связан с субъективными индивидуальными факторами (например, жизнестойкостью или уровнем психологического благополучия), чем с возрастом. В то время как наличие/отсутствие различных функций домашней среды (например, функциональность, возможность персонализации, удовлетворение базовых потребностей) может вносить разный вклад в мотивационную основу усиления или ослабления привязанности в зависимости от возраста (Резниченко, 2015).

\section{Основное исследование: определение конструктной валидности и взаимосвязи с другими показателями}

Целью основного исследования было проверить конвергентную валидность опросника путем корреляционного анализа связи между показателем привязанности к дому и авторским опросником «Функциональность домашней среды» (Нартова-Бочавер и др., 2015). Вкратце опишем последнюю методику. Опросник содержит 55 конструктов-утверждений, связанных с разноуровневыми функциями жилой среды, в которых нуждается человек (например, возможность хранить вещи, возможность динамической активности, возможность уединения и т.п.), оцениваемыми по 7-балльной порядковой шкале. Факторная структура опросника содержит 4 шкалы: 1) шкала Прагматичность (базовые функции дома, которые облегчают 
повседневную деятельность человека); 2) шкала Развитие (характеристики дома, отвечающие за развитие человека, снабжение сенсорной, когнитивной и социальной информацией); 3) шкала Стабильность (потенциал домашней среды в обеспечении стабильности, чувства комфорта); 4) шкала Защищенность (ресурсность домашней среды в обеспечении безопасного взаимодействия с социальным миром). Опросник прошел необходимые этапы валидизации (факторное подтверждение структуры, оценку валидности и надежности) и стандартизации. Опросник можно применять в реальной и идеальной модальности (описание функций реального либо идеального дома), что обеспечивается альтернативными установками, предлагаемыми в инструкции. В нашем исследовании мы выбрали в качестве предмета изучения функциональность реального образа дома.

Нас интересовало, каким образом привязанность к дому у мужчин и у женщин, а также у людей разного возраста связана с функциональностью актуальной домашней среды, т.е. какие функции дома оказываются наиболее значимыми для возникновения и поддержания комплекса позитивных чувств и переживаний по отношению к нему.

Сравнительный анализ выделенных групп строился на предположении о том, что взаимосвязи между функциональностью домашней среды и привязанностью к дому чувствительны к гендерному и возрастному факторам. Несмотря на то что непосредственное влияние пола и возраста на силу привязанности не изучалось, есть внушительное коли- чество отечественных и зарубежных исследований в смежных областях, демонстрирующих, что, например, мужчины и женщины по-разному оценивают пространство жизнедеятельности, а сама домашняя среда для женщин представляет более богатый ресурс позитивного функционирования, чем для мужчин (Дмитриева, 2013; Резниченко, 2013а). Также известно, что образ жилища в разных возрастах различен и меняется в зависимости от домашнего быта, уклада жизни, семейного статуса, вида деятельности или ценностных ориентаций личности (Meesters, 2009). Так, например, предполагается, что у детей и подростков привязанность к дому неустойчива и относительно слаба, поскольку у них еще не сформировались механизмы построения и поддержания личностной идентичности, недостаточно персонального опыта, чтобы оценить незаменимость, ценность и важность дома (Manzo, 2005).

Для достижения цели в рамках основного исследования на прежде выделенных группах (2 группы $(\mathrm{N}=168)$, сформированные по гендерному признаку, и три разновозрастных группы - юность $(\mathrm{N}=46)$, ранняя $(\mathrm{N}=42)$ и средняя взрослость $(\mathrm{N}=42))$ мы предприняли корреляционный анализ показателей шкалы Привязанности к дому и опросника Функциональности домашней среды. Напомним, что опросник Функциональности домашней среды включает четыре шкалы (Прагматичность, Развитие, Стабильность, Защищенность), однако мы включили в анализ еще одну переменную - общий показатель 
функциональности (ФДС), который складывается из значений остальных четырех показателей.

Подсчет коэффициента корреляции Ч. Спирмена подтвердил наличие значимых $(\mathrm{p} \leqslant 0.001)$ положительных связей между привязанностью и всеми функциональными характеристиками домашней среды (см. таблицу 3). Наиболее сильно привязанность к дому связана с общим показателем Функциональности домашней среды, а наименее сильно - с функцией Защищенности.

Чтобы проверить возрастную и гендерную специфику взаимосвязей между привязанностью к дому и функциональностью домашней среды, мы предприняли корреляционный анализ уже измеренных по всей выборке показателей Привязанности к дому и Функциональности, но в определенных нами ранее группах.

Корреляционный анализ в разновозрастных подгруппах демонстрирует, что в период юности (17-20 лет) переживание привязанности к дому менее сильно связано с функциональными характеристиками дома, чем на этапах ранней (21-30 лет) и средней взрослости (31-55 лет) (Бодалев, Реан, 2002). Между тем особенно сильные связи между функциональными характеристиками домашней среды и привязанностью к дому возникают в период средней взрослости (см. рисунок 1).

Привязанность к дому в юности имеет статистически высоко достоверные положительные взаимосвязи $(\mathrm{p} \leqslant 0.01)$ с обеспечением Стабильности $\left(r_{s}=0.58\right)$ и условиями для Развития $\left(r_{s}=0.53\right)$ в домашней среде, а также с ее Функциональностью в целом (ФДС) $\left(r_{s}=0.45\right.$, $p \leqslant 0.05)$. При этом Прагматичность и обеспечение чувства Защищенности не оказывают значимого влияния на переживание привязанности к дому. На этапе ранней взрослости Привязанность к дому наиболее тесно положительно связана $(p \leqslant 0.001)$ с общим уровнем Функциональности $\left(r_{s}=0.71\right)$ и Прагматичностью $\left(r_{s}=\right.$ $=0.70)$, в то время как функция обеспечения Защищенности $\left(r_{s}=0.63\right)$, Развивающий потенциал $\left(r_{s}=0.60\right)$ и Стабильность $\left(r_{s}=0.57\right)$ домашней среды являются умеренными положительными коррелятами $(p \leqslant 0.01)$ Привязанности к дому.

Наконец, в старшей возрастной подгруппе (31-50 лет) обнаружены статистически высоко значимые $(p \leqslant 0.001)$

Таблица 3

Связь показателя привязанности с переменными функциональности домашней среды (характеристиками домашней среды) $(\mathrm{N}=168 ; p \leqslant 0.001)$

\begin{tabular}{|l|c|}
\hline \multicolumn{1}{|c|}{ Характеристики домашней среды } & Показатели связи \\
\hline ФДС & 0.56 \\
\hline Прагматичность & 0.52 \\
\hline Развитие & 0.51 \\
\hline Стабильность & 0.52 \\
\hline Защищенность & 0.45 \\
\hline
\end{tabular}




\section{Возрастная специфика взаимосвязей между показателями привязанности} и функциональности домашней среды

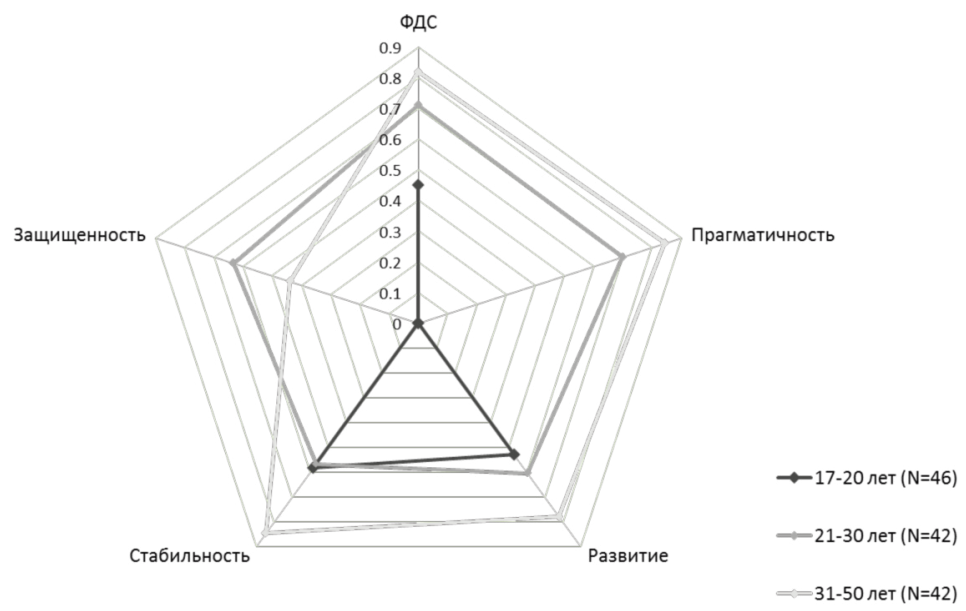

тесные положительные отношения между Привязанностью и Стабильностью $\left(r_{s}=0.85\right)$, Прагматичностью $\left(r_{s}=0.84\right)$, общим показателем Функциональности (ФДС) $\left(r_{s}=0.82\right)$ и возможностью Развития $\left(r_{s}=0.78\right)$ в домашней среде. В свою очередь, функция обеспечения чувства Защищенности в пределах домашнего пространства имеет слабую взаимосвязь $\left(r_{s}=0.44, p \leqslant 0.05\right)$ с переживанием Привязанность к дому.

Действительно, возрастной тренд отражает тот факт, что с возрастом функциональные характеристики домашней среды оказывают большее влияние на переживание привязанности к дому.

Мы предполагаем, что возрастная специфика мотивационных основ привязанности может быть обусловлена характерным для каждого возрастного периода своеобразием стиля и ритма жизни, ценностей, интересов и потребностей. Так, например, эпоха студенчества связана с резким расширением пространств жизнедеятельности и автономизацией от родного дома и его обитателей в целом: появляются возможности проживать или проводить бо́льшую часть времени в других местах (в общежитиях, в стенах университета, на студенческих посиделках и квартирниках). Разнообразие мест, их функциональных характеристик и форм проведения культурного, развлекательного и образовательного досуга вкупе с относительно слабой обремененностью домашними и семейными обязательствами в юношеском возрасте может временно ослаблять значимость функциональных характеристик домашней среды для поддержания привязанности к дому. Вместе с тем логично, что в этот возрастной период наиболее значимыми оказываются возможности развития и саморазвития в домашней среде, поскольку 
учебно-профессиональная деятельность наиболее актуальна.

Усиление взаимосвязи между привязанностью к дому и функциями домашней среды в периоды ранней и старшей взрослости связано с изменением семейной ситуации, появлением детей, увеличением зоны ответственности и обязательств, выполнение которых может быть оптимизировано за счет возможностей среды проживания.

Подсчет в женской и мужской подгруппе показал, что привязанность к дому у мужчин и женщин образует существенную положительную взаимосвязь $(p \leqslant 0.01)$ со всеми функциональными характеристиками домашней среды, однако у женщин в целом эти связи оказываются более слабыми, чем у мужчин (см. рисунок 2). Актуальный уровень привязанности в женской подгруппе наиболее сильно связан с обеспечением Защищенности и возможностью Развития в домашней среде. У мужчин привязанность к месту наиболее сильно взаимосвязана с Прагма- тичностью домашней среды, а функция обеспечения Защищенности является наименее сильным коррелятом, чем в женской подгруппе.

Возможно, меньшее разнообразие коррелятов внутри женской подгруппы обусловлено тем, что на уровень привязанности у женщин больше влияют иные характеристики дома (например, возможности заботы о семье или получения признания от домочадцев, условия для поддержания эмоционально позитивной атмосферы в доме), не включенные в факторную структуру опросника Функциональности домашней среды.

\section{Заключение}

В условиях экстенсификации социальной мобильности и миграционных процессов, ослабления территориальной и социокультурной идентичности у местных сообществ изучение привязанности к месту (к дому) имеет важное значение в теоретическом и прикладном плане. Инструментальное изучение привязанности к дому,

Рисунок 2

Гендерная специфика взаимосвязей между показателями привязанности и функциональности домашней среды в разновозрастных группах (при уровне значимости $p \leqslant 0.01$ )

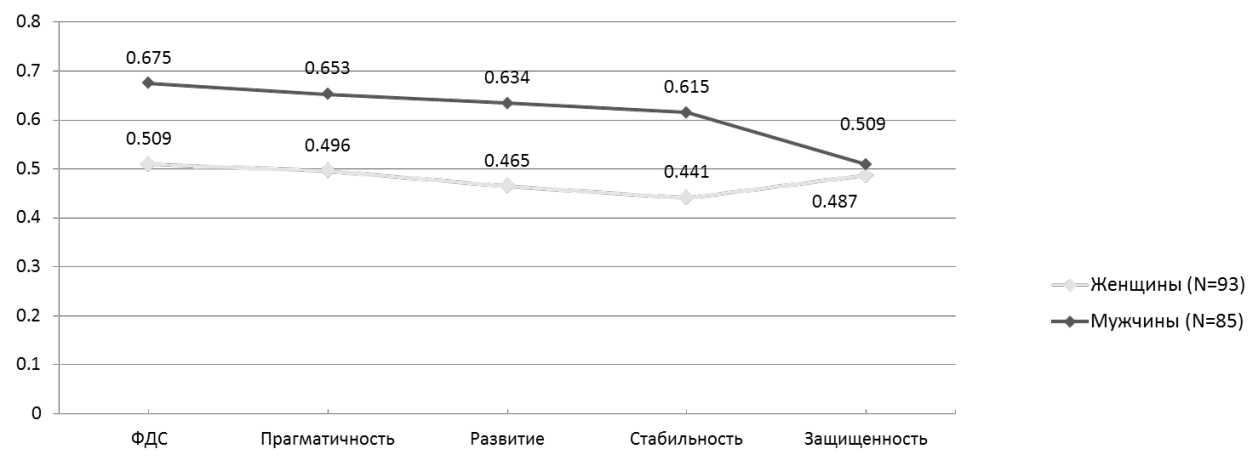


определяющее переживания субъекта, связанные с его жилищем, не только имеет принципиальное значение в оценке меры дружественности среды и удовлетворенности жизнедеятельностью в ней, но и может быть одним из косвенных показателей, предопределяющих уровень психологического благополучия личности. На сегодняшний день опросник Привязанности к дому является единственным по своему содержанию и предмету изучения, измеряющим привязанность человека к жилой среде. Опросник является достаточно надежным инструментом, хотя и требует более детальной верификации на объемных выборках. Например, необходимы более тщательный анализ причин слабой чувствительности конструкта привязанности к дому к возрастному фактору, а также оценка содержательной валидности. Также требуется оценка надежности опросника, поскольку переживание привязанности к дому как эмоциональное отношение может иметь ситуативный характер. Разработанный опросник не выявляет релевантность мотивационных основ привязанности к дому, а измеряет силу значимости дома для его обитателя.

Отличаясь лаконичностью и простотой анализа данных, опросник может стать полезным дополнительным инструментом для исследователей в области психологии домашней среды, архитектуры и социальных наук. Опросник позволяет изучить, каким образом объектные, т.е. средовые, характеристики домашней среды влияют на субъективное отношение к дому и, наоборот, как привязанность к дому сказывается на позитивном функционировании личности.

\section{Литература}

Бодалев А. А., Реан А. А. (2002). Акмеологический подход к периодизации возрастного развития человека: основные характеристики человека в период средней взрослости. В кн. А. А. Деркач (ред.), Акмеология (с. 206-209). М.: Изд-во РАГС.

Дмитриева, Н. С. (2013). Модель жизненного пространства у подростков: предпосылки и направления исследования. Актуальные проблемъ психологического знания, 28(3), 90-99.

Драганова, М., Староста, П., Столбов, В. (2002). Социальная идентификация жителей сельских поселений и малых городов Восточной Европы. Социологические исследования, 2, 52-60.

Нартова-Бочавер, С. К. (2006). Теория приватности как направление зарубежной психологии. Психологический журнал, 27(5), 28-39.

Нартова-Бочавер, С. К. (2016). Принцип дополнительности в психологии: взаимодействие дома и его обитателей. В кн. А. Л. Журавлев, М. И. Воловикова, Н. Е. Харламенкова (ред.), Психологические исследования личности: история, современное состояние, перспективы (c. 192-214). М.: Изд-во «Институт психологии РАН».

Нартова-Бочавер, С. К., Дмитриева, Н. С., Резниченко, С. И., Кузнецова, В. Б., Брагинец, Е. И. (2015). Метод оценки дружественности жилища: опросник «Функциональность домашней среды». Психологический журнал, 36(4), 71-83.

Резниченко, С. И. (2013а). Механизмы привязанности к жилому пространству у детей младшего школьного возраста. Актуальные проблемы психологического знания, 2, 24-40. 
Резниченко, С. И. (2013б). Образ жилого пространства как социально-психологический феномен. В кн. З. И. Рябикина, В. В. Знаков (ред.), Личность и бытие: субъектный подход (к 80-летию со дня рождения А. В. Брушлинского): материаль VI Всероссийской научнопрактической конферениии (с иностранным участием) (с. 77-79). М./Краснодар: Кубанский государственный университет.

Резниченко, С. И. (2014). Привязанность к месту и чувство места: модели и феномены. Социальная психология и общество, 3, 15-27.

Резниченко, С. И. (2015). Влияние функциональности жилища на переживание привязанности к домашней среде. В кн. 7-я Российская конферениия по экологической психологии. Тезисы (28-29 сентября 2015 года, Москва) (с. 374-375). М.: УМК «Психология».

Abdi, H., \& Valentin, D. (2007). Multiple correspondence analysis. In N. Salkind (Ed.), Encyclopedia of measurement and statistics (pp. 652-658). Thousand Oaks, CA: SAGE Publications, Inc.

Arbuckle, J. L., \& Worthke, W. (1999). Amos 4.0 User's Guide. Chicago, IL: SmallWaters, Inc.

Bow, V., \& Buys, L. (2003). Sense of community and place attachment: The natural environment plays a vital role in developing a sense of community. Paper presented to Social Change in the 21st Century Conference, Centre for Social Change Research, Queensland University of Technology, Queensland, Australia.

Broudehoux, A. M. (2001). Image making, city marketing and the anesthetization of social inequality in Rio de Janeiro. In N. AlSayyad (Ed.), Consuming tradition, manufacturing heritage. Global norms and urban forms in the age of tourism (pp. 273-296). London/New York: Routledge.

Hou, J.-S., Lin, C.-H., Morais, D. B. (2005). Antecedents of attachment to a cultural tourism destination: The case of Hakka and Non-Hakka Taiwanese visitors to Pei-Pu, Taiwan. Journal of Travel Research, 44(2), 221-233.

Inglis, J. (2008). Using human-environment theory to investigate human valuing in protected area management (Doctoral dissertation). Retrieved from http://vuir.vu.edu.au/id/eprint/1513

Johnson, C. Y. (1998). A consideration of collective memory in African American attachment to wildland recreation places. Research in Human Ecology, 5(1), 5-15.

Jorgensen, B. S., \& Stedman, R. C. (2006). A comparative analysis of predictors of sense of place dimensions: Attachment to, dependence on, and identification with lakeshore properties. Journal of Environmental Management, 79(3), 316-327.

Kaltenborn, B. P., \& Bjerke, T. (2002). Associations between landscape preferences and place attachment: a study in Roros, Southern Norway. Landscape Research, 27(4), 381-396.

Manzo, L. C. (2005). For better or worse: exploring multiple dimensions of place meaning. Journal of Environmental Psychology, 25, 67-86.

Meesters, J. (2009). The meaning of activities in the dwelling and residential environment: A structural approach in people-environment relations (Sustainable Urban Areas, Vol. 27). Delft: Delft University Press.

Orr, D. W. (1994). The coming biophilia revolution. Earth Island Journal, 9(2), 38-40.

Pruneau, D., Chouinard, O., Arsenault, C. \& Breau, N. (1999). An intergenerational education project aiming at the improvement of people's relationship with their environment. International Research in Geographical and Environmental Education, 8(1), 26-39.

Rodman, M. C. (2003). Empowering place: multilocality and multivocality. Locating culture. In S. M. Low, D. Lawrence-Zúniga (Eds.), The anthropology of space and place (pp. 204-223). Oxford: Blackwell Publishing Ltd.

Rollero, C., \& De Piccoli, N. (2010). Does place attachment affect social well-being? Revue Européenne de Psychologie Appliquée/European Review of Applied Psychology, 60(4), 233-238. 
Stokols, D., \& Shumaker, S. A. (1981). People in places: A transactional view of settings. In J. Harvey

(Ed.), Cognition, social behaviour, and the environment (pp. 441-488). Hillsdale, NJ: Lawrence

Erlbaum Associates, Inc.

Tuan, Y. F. (1977). Space and place: The perspective of experience. Minneapolis: University of Minnesota Press.

Williams, D., Patterson, M. E., Roggenbuck, J. W., \& Watson, A. E. (1992). Beyond the commodity metaphor: Examining emotional and symbolic attachment to place. Leisure Science, 14, 29-46.

Williams, D., \& Stewart, S. I. (1998). Sense of place: An elusive concept that is finding a home in ecosystem management. Journal of Forestry, 96(5), 18-23.

\section{Опросник привязанности к дому}

Приложение

Данный опросник позволит изучить отношение людей к своему жилью в целом и к его содержанию в частности.

Опросник не предполагает верных и неверных ответов. Пожалуйста, ответьте на каждый вопрос, основываясь на собственных чувствах. Оцените степень своего согласия/несогласия с каждым из утверждений, используя пятибалльную шкалу, где:

1 - совершенно не согласен; 2 - скорее не согласен; 3 - трудно ответить; 4 - скорее согласен; 5 - совершенно согласен.

\begin{tabular}{|c|c|c|c|c|c|c|}
\hline & Мой дом & 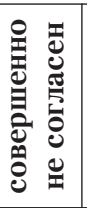 & 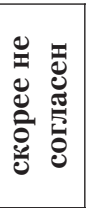 & 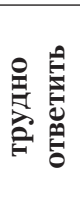 & 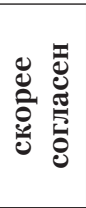 & 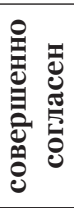 \\
\hline & & 1 & 2 & 3 & 4 & 5 \\
\hline 1 & Я чувствую, что мой дом - это часть меня & & & & & \\
\hline 2 & $\begin{array}{l}\text { Мой дом - лучшее место заниматься тем, что мне } \\
\text { нравится }\end{array}$ & & & & & \\
\hline 3 & Мой дом - это особенное место для меня & & & & & \\
\hline 4 & $\begin{array}{l}\text { Ни одно другое место не может сравниться с моим } \\
\text { домом }\end{array}$ & & & & & \\
\hline 5 & Мой дом и я очень похожи друг на друга & & & & & \\
\hline 6 & $\begin{array}{l}\text { Я получаю большее удовлетворение, находясь в } \\
\text { собственном доме, нежели в других местах }\end{array}$ & & & & & \\
\hline 7 & Я очень привязан к своему дому & & & & & \\
\hline 8 & $\begin{array}{l}\text { То, чем я занимаюсь дома, важнее того, что я } \\
\text { делаю в других местах }\end{array}$ & & & & & \\
\hline 9 & Видящие мой дом могут узнать обо мне многое & & & & & \\
\hline
\end{tabular}




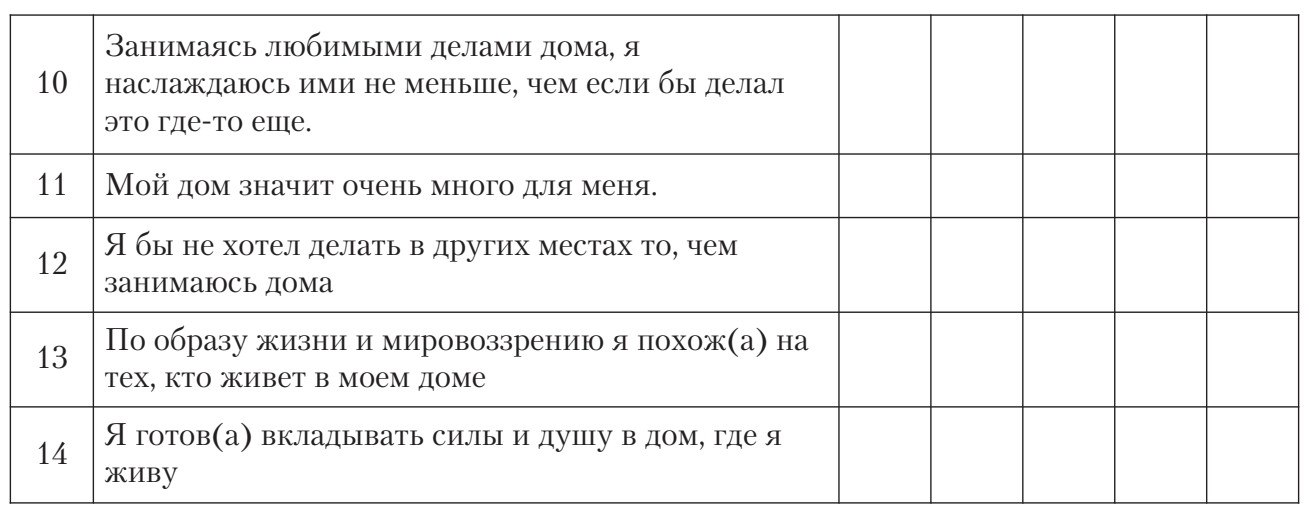
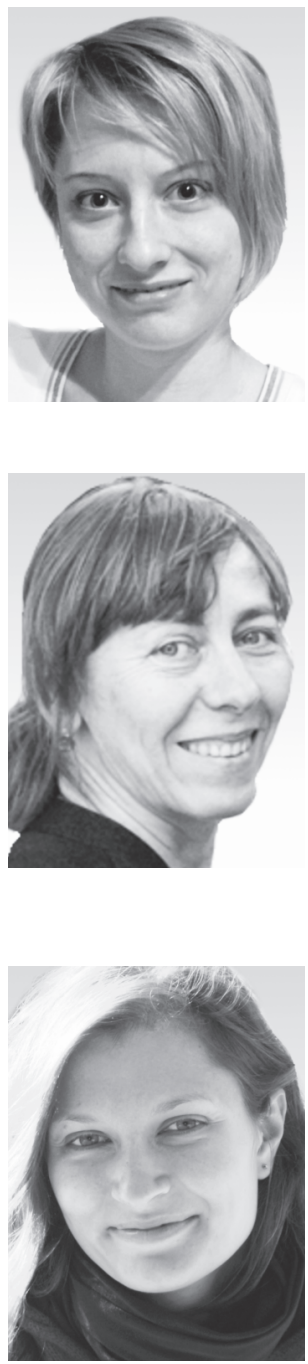

Резниченко София Ивановна - научный сотрудник ФГБОУ ВО «Московский государственный психолого-педагогический университет», кандидат психологических наук.

Сфера научных интересов: экологическая психология, субъектносредовая психология, клиническая и специальная психология. Контакты: sofya_292@list.ru
Нартова-Бочавер Софья Кимовна - профессор, факультет социальных наук, департамент психологии, Национальный исследовательский университет «Высшая школа экономики», доктор психологических наук.

Сфера научных интересов: психология личности, индивидуальные различия, психология морали и справедливости, позитивная психология, экологическая психология.

Контакты: s-nartova@yandex.ru

Кузнецова Валерия Борисовна - научный сотрудник ФГБУ НИИ физиологии и фундаментальной медицины СО РАМН, кандидат психологических наук.

Сфера научных интересов: психология личности, психическое здоровье, дети и подростки.

Контакты: vb.kuznetsova@gmail.com 


\title{
The Instrument for Assessment of Home Attachment
}

\section{Sofia I. Reznichenko ${ }^{a}$, Sofia K. Nartova-Bochaver ${ }^{\mathrm{b}}$, Valeria B. Kuznetsova ${ }^{c}$}

${ }^{a}$ Moscow State University of Psychology and Education, 29 Sretenka str., Moscow, 127051, Russian Federation

${ }^{b}$ National Research University Higher School of Economics, 20 Myasnitskaya str., Moscow 101000 Russian Federation

'State Scientific-Research Institute of Physiology and Basic Medicine, 4 Timakova str., Novosibirsk, 630117, Russian Federation

\begin{abstract}
The high relevance of research on home attachment as an interdisciplinary and multilayered phenomenon is substantiated, which reflects the reciprocity of relationships between human and his/her environment and has regulatory and valeological meaning for personality. The problematic of the home attachment phenomenon is meticulously analyzed, which appears to be a specific type of place attachment; the multiple-level system of the notion of "home" as an object of functional, emotional and symbolic attachment is discussed, the main structural components that form it are considered, such as identification with place, sense of place, dependence on place. The methodological backgrounds and the process of development of the Home Attachment Questionnaire are articulated, its conceptual, empirical and factor models are described. The procedure and the results of the pilot study $\left(\mathrm{N}=287, \mathrm{M}_{\text {age }}=21.5, \mathrm{SD}_{\mathrm{age}}=9.2\right)$ on questionnaire validation (factor analysis, internal consistency) are provided, as well as descriptive statistics. The results of the main study are given, which objective was to analyze the construct validity of the questionnaire. Validation included the verification of correlations between home attachment and level of functionality of home environment. The analysis of age specifics is described (three age groups were determined: youth, young and middle aged adults), which reflects the fact that relationships between home attachment and functionality strengthen with age. The relationships between home attachment and functionality are also moderated by gender: home attachment in women is linked to safety and possibility for personal growth in home environment, while in men it is linked to convenience and comfort of the dwelling. In conclusion, possibilities, limitations and prospects of use of the questionnaire are discussed.
\end{abstract}

Keywords: ecological psychology, home attachment, questionnaire, convergent validity, age and gender specifics.

Acknowledgements. The research was conducted with the assistance of the Russian Science Foundation (project № 14-18-02163).

\section{References}

Abdi, H., \& Valentin, D. (2007). Multiple correspondence analysis. In N. Salkind (Ed.), Encyclopedia of measurement and statistics (pp. 652-658). Thousand Oaks, CA: SAGE Publications, Inc.

Arbuckle, J. L., \& Worthke, W. (1999). Amos 4.0 User's Guide. Chicago, IL: SmallWaters, Inc. 
Bodalev, A. A., \& Rean, A. A. (2002). Akmeologicheskii podkhod k periodizatsii vozrastnogo razvitiya cheloveka: osnovnye kharakteristiki cheloveka v period srednei vzroslosti [Acmeological approach to periodization of personal development: basic characteristics of a person in middle adulthood]. In A. A. Derkach (Ed.), Akmeologiya [Akmeology] (pp. 206-209). Moscow: Russian Academy of Public Administration.

Bow, V. \& Buys, L. (2003). Sense of community and place attachment: The natural environment plays a vital role in developing a sense of community. Paper presented to Social Change in the 21st Century Conference, Centre for Social Change Research, Queensland University of Technology, Queensland, Australia.

Broudehoux, A. M. (2001). Image making, city marketing and the anesthetization of social inequality in Rio de Janairo. In N. AlSayyad (Ed.), Consuming tradition, manufacturing heritage. Global norms and urban forms in the age of tourism (pp. 273-296). London/New York: Routledge.

Dmitrieva, N. S. (2013). The model of teenager life space: Prerequisites and directions of research. Aktual'nye Problemy Psikhologicheskogo Znaniya, 28(3), 90-99. (in Russian).

Draganova, M., Starosta, P., \& Stolbov, V. (2002). Sotsial'naya identifikatsiya zhitelei sel'skikh poselenii i malykh gorodov Vostochnoi Evropy [Social identification of people living in rural settlements and small cities of Eastern Europe]. Sotsiologicheskie Issledovaniya, 2, 52-60.

Hou, J.-S., Lin, C.-H., Morais, D. B. (2005). Antecedents of attachment to a cultural tourism destination: The case of Hakka and Non-Hakka Taiwanese visitors to Pei-Pu, Taiwan. Journal of Travel Research, 44(2), 221-233.

Inglis, J. (2008). Using human-environment theory to investigate human valuing in protected area management (Doctoral dissertation). Retrieved from http://vuir.vu.edu.au/id/eprint/1513

Johnson, C. Y. (1998). A consideration of collective memory in African American attachment to wildland recreation places. Research in Human Ecology, 5(1), 5-15.

Jorgensen, B. S., \& Stedman, R. C. (2006). A comparative analysis of predictors of sense of place dimensions: Attachment to, dependence on, and identification with lakeshore properties. Journal of Environmental Management, 79(3), 316-327.

Kaltenborn, B. P., \& Bjerke, T. (2002). Associations between landscape preferences and place attachment: a study in Roros, Southern Norway. Landscape Research, 27(4), 381-396.

Manzo, L. C. (2005). For better or worse: exploring multiple dimensions of place meaning. Journal of Environmental Psychology, 25, 67-86.

Meesters, J. (2009). The meaning of activities in the dwelling and residential environment: A structural approach in people-environment relations (Sustainable Urban Areas, Vol. 27). Delft: Delft University Press.

Nartova-Bochaver, S. K. (2006). Theory of privacy as a line of investigation in the foreign psychology. Psikhologicheskii Zhurnal, 27(5), 28-39.

Nartova-Bochaver, S. K. (2016). Printsip dopolnitel'nosti v psikhologii: vzaimodeistvie doma i ego obitatelei [The principle of complementarity in psychology: home and its inhabitants interaction]. In A. L. Zhuravlev, M. I. Volovikova, N. E. Kharlamenkova (Eds.), Psikhologicheskie issledovaniya lichnosti: istoriya, sovremennoe sostoyanie, perspektivy [Psychological research on personality: history, current status and prospects] (pp. 192-214). Moscow: Institute of Psychology of Russian Academy of Sciences.

Nartova-Bochaver, S. K., Dmitrieva, N. S., Reznichenko, S. I., Kuznetsova, V. B., \& Braginets, E. I. (2015). The instrument for assessment of dwelling friendliness: "Functionality of home environment" questionnaire. Psikhologicheskii Zhurnal, 36(4), 71-83.

Orr, D. W. (1994). The coming biophilia revolution. Earth Island Journal, 9(2), 38-40. 
Pruneau, D., Chouinard, O., Arsenault, C. \& Breau, N. (1999). An Intergenerational education project aiming at the improvement of people's relationship with their environment. International Research in Geographical and Environmental Education, 8(1), 26-39.

Reznichenko, S. I. (2013a). The mechanisms of junior school pupils' devotion to their living space. Aktual'nye Problemy Psikhologicheskogo Znaniya, 2, 24-40. (in Russian).

Reznichenko, S. I. (2013b). Obraz zhilogo prostranstva kak sotsial'no-psikhologicheskii fenomen [The image of the living space as a socio-psychological phenomenon]. In Z. I. Ryabikina \& V. V. Znakov (Eds.), Lichnost' i bytie: sub"ektnyi podkhod (k 80-letiyu so dnya rozhdeniya A. V. Brushlinskogo): materialy VI Vserossiiskoi nauchno-prakticheskoi konferentsii (s inostrannym uchastiem) [Personality and being: subjective approach (to the 80th anniversary of A. V. Bruschlinsky): Reports of the VI All-Russian scientific-practical conference (with foreign participation)] (pp. 77-79). Moscow/Krasnodar: Kuban State University.

Reznichenko, S. I. (2014). Attachment to place and sense of place: Models and phenomena. Social Psychology and Society, 3, 15-27.

Reznichenko, S. I. (2015). Vliyanie funktsional'nosti zhilishcha na perezhivanie privyazannosti k domashnei srede [The impact of functionality of the dwelling on experiencing attachment to home environment]. In 7-ya Rossiiskaya konferentsiya po ekologicheskoi psikhologii. Tezisy (28-29 sentyabrya 2015 goda, Moskva) [7th Russian conference on ecological psychology. Abstracts (September 28-29, 2015, Moscow)] (pp. 374-375). Moscow: UMK "Psikhologiya".

Rodman, M. C. (2003). Empowering place: multilocality and multivocality. Locating culture. In S. M. Low, D. Lawrence-Zúniga (Eds.), The anthropology of space and place (pp. 204-223). Oxford: Blackwell Publishing Ltd.

Rollero, C., \& De Piccoli, N. (2010). Does place attachment affect social well-being? Revue Européenne de Psychologie Appliquée/European Review of Applied Psychology, 60(4), 233-238.

Stokols, D., \& Shumaker, S. A. (1981). People in places: A transactional view of settings. In J. Harvey (Ed.), Cognition, social behaviour, and the environment (pp. 441-488). Hillsdale, NJ: Lawrence Erlbaum Associates, Inc.

Tuan, Y. F. (1977). Space and place: The perspective of experience. Minneapolis: University of Minnesota Press.

Williams, D., Patterson, M. E., Roggenbuck, J. W., \& Watson, A. E. (1992). Beyond the commodity metaphor: Examining emotional and symbolic attachment to place. Leisure Science, 14, 29-46.

Williams, D., \& Stewart, S. I. (1998). Sense of place: An elusive concept that is finding a home in ecosystem management. Journal of Forestry, 96(5), 18-23.

Sofia I. Reznichenko - scientist researcher, Moscow State University of Psychology and Education, Ph.D.

E-mail: sofya_292@list.ru

Sofia K. Nartova-Bochaver - professor, Faculty of Social Sciences, School of Psychology, National Research University Higher School of Economics, D. Sc.

E-mail: s-nartova@yandex.ru

Valeria B. Kuznetsova - scientist researcher, Research Institute of Physiology and Basic Medicine, Siberian Branch of the Russian Academy of Medical Sciences, Ph.D.

E-mail: vb.kuznetsova@gmail.com 